\title{
Conservative management of spontaneous rupture of the urinary bladder: comment
}

\author{
Christopher C. K. Ho
}

Published online: 11 June 2011

(C) The International Urogynecological Association 2011

\section{Dear Editor,}

Spontaneous bladder ruptures are bladder ruptures which occur without trauma. Besides malignancy, irradiation, large ureterovesical stones, binge alcohol drinking, continuous bladder irrigation, postpartum and pelvic organ prolapsed as mentioned by Abu Mahfouz et al. [1] it can also be a complication of tuberculosis [2].

In this case, the patient presented with 1-day history of acute urinary retention, 3-day history of right iliac fossa (RIF) pain and irreducible pelvic organ prolapse. On examination, the abdomen was distended and there was mild RIF tenderness. What probably happened was that due to the pelvic organ prolapsed, there was bladder outlet obstruction resulting in acute urinary retention. It could have ruptured when she had the RIF pain, which was 3 days prior to consultation. However, it was temporarily sealed off by the uterus resulting in another episode of urinary retention when she came for consultation. With distension of the bladder, the seal leaked, explaining for the minimal urine drained via the urinary catheter. The raised creatinine and urea could be due to peritoneal reabsorption of the urine.

Conservative management of spontaneous intraperitoneal bladder rupture has also been reported by Basiri et al. [3]. In

An author's reply to this comment is available at doi:10.1007/s00192011-1479-z.

C. C. K. Ho $(\bowtie)$

Urology Unit, Department of Surgery,

Universiti Kebangsaan Malaysia Medical Centre,

Bandar Tun Razak, 56000 Cheras,

Kuala Lumpur, Malaysia

e-mail: chrisckho2002@yahoo.com his case, he argued that conservative management was opted due to the known complication rate of performing surgery on irradiated tissues. However, the patient reported by Abu Mahfouz et al. [1] was a healthy lady and there was already a collection in the pelvis which was a potential focus of infection. There was no mention of fever or the size of the collection but I feel it should be drained. I am also of the opinion that early laparotomy and repair of the bladder wall should have been done since she is premorbidly healthy, the defect in the bladder was large and the perforation was detected early.

However, I will have to agree with the authors that since the patient was clinically well and had in fact improved with an indwelling catheter, a trial of conservative management could be attempted with the option of bladder repair if patient deteriorates. Close observation of the patient is mandatory. Recurrence does occur in spontaneous bladder ruptures treated conservatively [4].

\section{References}

1. Abu Mahfouz I, Sayer T, Phillips C (2011) Conservative management of spontaneous rupture of the urinary bladder. Int Urogynecol J 22:629-631. doi:10.1007/s00192-010-1319-6

2. Kong CH, Ali SA, Singam P, Hong GE, Cheok LB, Zainuddin ZM (2010) Spontaneous bladder perforation: a rare complication of tuberculosis. Int J Infect Dis 14(Suppl 3):e250-e252

3. Basiri A, Radfar MH (2008) Conservative management of early bladder rupture after postoperative radiotherapy for prostate cancer. Urol J 5(4):269-271

4. Kaneko T, Nozawa T, Owari Y (2000) Recurrent spontaneous rupture of the urinary bladder: a case report. Hinyokika Kiyo 46 (2):137-139 